\title{
Pakistan Poultry Industry Growth and Challenges
}

\author{
Iram Liaqat* \\ Department of Zoology, Pakistan \\ *Corresponding author: Iram Liaqat, Department of Zoology, GC University, Lahore, Pakistan \\ Submission: 眥January 03, 2018; Published: 非January 24, 2018
}

\begin{abstract}
Poultry Industry is largest agro based segment of Pakistan contributing 1.3\% to the national GDP. More than $67 \%$ of Pakistani population lives in rural areas using agriculture means. It was before 1960 the native breed "Desi" was mainly raised with a maximum of 73 eggs production per year under local conditions. After that commercial poultry production started and has been providing a major source of daily proteins to the Pakistani population. It generates employment and provides source of income to more than 1.5 million people of Pakistan through direct and/or indirect means. Though it has faced several challenges such as disease outbreaks and retail price fluctuations and there is no sufficient data regarding its important role in the country's economy. Available data lacks reliability and accurate statistical analysis. This mini review focuses poultry industry, its growth, current status and various challenges which Pakistan is currently facing
\end{abstract}

Abbreviations: HPS: Hydro Pericardium Syndrome; WHO: World Health Organization; PAWS: Pakistan Animal Welfare Society; PARC: Pakistan Agricultural Research Council

\section{Introduction}

Since beginning, backyard farming is a common practice in Pakistan through which total poultry production in Pakistan was established. However, rural poultry farming have suffered drastically without

I. Labor skills

II. Knowledge about poultry diseases

III. Proper training and

IV. Marketing awareness

Now various incentives and compensations provided by the Pakistani government and advanced farming practices with proper measures including income tax exemptions, advanced farming instruments, funded research, duty free imports, better feeding ingredients, disease control chemicals and Interest free loans have caused economic boom to poultry sector commercially. One significant factor was to establish the Directorate of Poultry Production in Karachi.

Poultry-friendly policies by the Government and profits, this industry have become a profitable enterprise in Pakistan. From 1971 to 1980 , the poultry industry experienced $177 \%, 271 \%$ and $297 \%$ overall growth in total number of birds, total poultry meat production and total number of eggs, respectively [1]. Present turnover of Pakistan Poultry Industry is about 750 Billion rupees. There are nearly 352 hatcheries that have been set in the country with a capacity of nearly 346 million day-old chicks on an annual basis. The population in terms of poultry is estimated to be nearly 319 million, out of which more than $44 \%$ is coming from the rural sectors. The population includes 160 million broilers, 17 million layers, 5 million breeding stocks and 13154 farms.

Diseases outbreaks and decreased productivity due to climatic stress were the major challenges which poultry industry in Pakistan faced during 1981-1990. Hydro Pericardium Syndrome (HPS) appeared in 1990 and caused a huge damage to broiler and broiler breeder flocks. Gumboro appeared in 1991-and adversely effected broiler, layer and parent flocks. Afterwards, outbreak of Avian Influenza in Murree and Abbotabad in 1995 affected the parent flocks and caused up to $80 \%$ mortality $[2,3]$. This led to investigating new approached including vaccination and biosecurity. Various agricultural and veterinarians sectors did research and played vital role in this area [4]. Despite lack of proper planning and certain other pitfalls, poultry industry keep growing and successfully established it's self by 1999.

Up to 2004, Poultry industry showed significant growth with great profits. It's the only cheapest available sources of animal protein in Pakistan in terms of eggs and meat [4]. On an average, now a laying bird is able to produce nearly 250 eggs yearly and has a weight of about $1.2 \mathrm{~kg}$ within 8 weeks of its birth. A clear indicator about the potential for growth and expansion of poultry industry can be estimated that about 6.5 million thousand eggs per year are being produced commercially. However, in developed countries where these figures are $41 \mathrm{~kg}$ meat and 300 eggs, Pakistan is having $5 \mathrm{~kg}$ and 51 eggs per year [5]. World Health Organization (WHO) recommends a requirement for animal protein is $27 \mathrm{~g}$ per person, compared to Pakistan, where it is only $17 \mathrm{~g}$ [6]. Estimated rate increase in population is $2.03 \%$ per annum which demands more 
poultry growth. Hence certain approaches such as establishment of more hatcheries and control sheds, specialized technical training to the farmers, specialized chemicals provision for the treatment of various debilitating diseases, modification of traits through modes of cross breeding, more funds transfer to rural area are in need to be made. In conclusion, Poultry industry in Pakistan is contributing significantly to its economy. Government should make every effort to introduce new policies and incentives for controlling fluctuating prices by switching towards value added products. Additionally, proper bio security measures and control of various disease outbreak will help to place poultry industry in international market without real damage.

In this regards, the welfare implications of a particular management procedure, including the health, productivity, physiology, and behavior of the poultry in Pakistan has been ensured by practicing certain rules. Pakistan Poultry Association was established in 1979 to promote lobbying to uplift the status of the industry and farmers. Established of Pakistan animal welfare society (PAWS), a non-profit organization working for animal welfare in Pakistan in 2004 was also a step for the said purpose. This works to create a more just and equitable relationship between humans and animals in Pakistan. All its funds are utilized in rescuing and treating animals as well as awareness raising and advocacy work. Among other factors, commercialization of the battery cage system for laying hens in the 1950's. Since then, it has become the most accepted method for maintaining hens. Cages provide the egg producer with an efficient and cost-effective means of collecting eggs, disposing of wastes, reducing feed wastage, maintaining an adequate environmental temperature, and inspecting the condition of individual birds.

Because of the behavioral restrictions that are imposed upon the birds, cages are always under severe criticism due to restricted behaviors like nesting, perching, and dust bathing. Space allowances for laying hens is another extremely controversial topic I. In their "Recommended Guidelines of Husbandry Practices for Laying Chickens," the United Egg Producers suggest 48 square inches per bird as a minimum space requirement for caged hens; however, the European Community has mandated a minimum allowance of
75 square inches per bird. (In many European countries, heavier bodied brown egg layers are preferred to the lighter bodied white egg layers used in the United States. Both the European and UEP guidelines recommend providing a minimum space allowance of 12 square inches per pound of live weight, although it is more common to express space allowances on a per-bird basis.)

\section{Conclusion}

Several health and welfare problems related to rapid growth rate are seen predominantly in meat-type birds. Pakistan agricultural research council (PARC), is working hard in various field including establishment of small/medium scale poultry farms, technical knowhow to the rural poultry farmers regarding management, vaccination and disease prevention, technology transfer to both public and private wildlife management and conservation organizations and wildlife farmers for in-situ wildlife conservation and provision of high producing desi chicks to the rural / domestic poultry farmers. However, the general law and order situation in Pakistan has been a major factor contributing to poor growth of the local poultry industry, especially in the last 10 years. Long hours of power shortage, poor quality feed with mycotoxins, lack of proper biosecurity plans and fluctuating prices, caused great damage to the growth of the poultry industry in Pakistan.

\section{References}

1. GOP (2013) Federal Bureau of Statistics, Ministry of Finance, Government of Pakistan, Pakistan.

2. Akhtar S (1994) Hydro-pericardium Syndrome in broiler chicken in Pakistan. World's Poultry Science Journal 50(2): 177-182.

3. Anjum AD, Sabri GS, Jamshidi K (1994) Occurrence spread and control of infectious bursal disease in Pakistan. Proceedings of $1^{\text {st }}$ PPA-PVMA Punjab, International Poultry Conference, pp. 57-59.

4. PPA (2013) Pakistan Poultry Industry has very strong roots in Pakistan as we just can't see our dinner or lunch without Chicken. Pakistan Poultry Association, Pakistan.

5. PPA (2013) Present Status of Poultry Sector. Pakistan Poultry Association, Pakistan.

6. Memon NA (2012) Poultry: Country's second-largest industry. Exclusive on Poultry. 